\title{
Oncogenic osteomalacia secondary to glomus tumor
}

\author{
Rishi Raj(D1, Samaneh Hasanzadeh², Mitra Dashtizadeh², Mohammadreza Kalantarhormozi², \\ Katayoun Vahdat², Mohammad Hossein Dabbaghmanesh³, Iraj Nabipour², \\ Mohammdreza Ravanbod 3 , Majid Assadi2 ${ }^{2}$ Basir Hashemi ${ }^{3}$ and Kamyar Asadipooya 4 \\ 1Pikeville Medical Center, Pikeville, Kentucky, USA, 2Bushehr University of Medical Sciences, Bushehr, Iran, ${ }^{3 S h i r a z}$ \\ University of Medical Sciences, Shiraz, Iran, and 4University of Kentucky, Lexington, Kentucky, USA \\ Correspondence \\ should be addressed \\ to R Raj \\ Email \\ rishiraj91215@gmail.com
}

\section{Summary}

Oncogenic osteomalacia secondary to glomus tumor is extremely rare. Localization of causative tumors is critical as surgical resection can lead to a complete biochemical and clinical cure. We present a case of oncogenic osteomalacia treated with resection of glomus tumor. A 39-year-old woman with a history of chronic sinusitis presented with chronic body ache and muscle weakness. Biochemical evaluation revealed elevated alkaline phosphatase hypophosphatemia, increased urinary phosphate excretion, low calcitriol, and FGF23 was unsuppressed suggestive of oncogenic osteomalacia. Diagnostic studies showed increase uptake in multiple bones. Localization with MRI of paranasal sinuses revealed a sinonasal mass with concurrent uptake in the same area on the octreotide scan. Surgical resection of the sinonasal mass was consistent with the glomus tumor. The patient improved both clinically and biochemically postoperatively. Along with the case of oncogenic osteomalacia secondary to a glomus tumor, we have also discussed in detail the recent development in the diagnosis and management of oncogenic osteomalacia.

\section{Learning points:}

- Tumor-induced osteomalacia is a rare cause of osteomalacia caused by the secretion of FGF23 from mesenchymal tumors.

- Mesenchymal tumors causing TIO are often difficult to localize and treat.

- Resection of the tumor can result in complete resolution of biochemical and clinical manifestations in a very short span of time.

- Glomus tumor can lead to tumor induced osteomalacia and should be surgically treated.

\section{Background}

Tumor-induced osteomalacia (TIO), also known as oncogenic osteomalacia, is a rare and acquired paraneoplastic syndrome. TIO is characterized by hypophosphatemia, increased urinary phosphate excretion and low calcitriol levels due to FGF23, secreted by the tumor (1). This ultimately results in hypophosphatemic osteomalacia and can have variable manifestations ranging from diffuse musculoskeletal pain to bone fractures. Despite obvious diagnosis among patients presenting with aforementioned clinical and biochemical findings, the subsequent localization of mesenchymal tumor often remains challenging. This results in a significant delay in the diagnosis and treatment of these patients. Herein, we are presenting a case of TIO caused by glomus tumor localized in the right sinus cavity. 


\section{Case presentation}

A 39-year-old woman with a past medical history of chronic sinusitis presented with progressively worsening generalized body pain and muscle weakness of 8 months duration. Patient was afebrile and hemodynamically stable on presentation. On musculoskeletal examination, she had decreased muscle strength in bilateral upper and lower extremities. Rest of the physical examination was unremarkable except for the presence of a congenital cleft palate.

\section{Investigation}

Laboratory workup revealed elevated alkaline phosphatase $603 \mathrm{U} / \mathrm{L}(44-147 \mathrm{U} / \mathrm{L})$, low serum phosphate $1.5 \mathrm{mg} /$ $\mathrm{dL}(3.5-5.0 \mathrm{mg} / \mathrm{dL})$, normal serum calcium $8.9 \mathrm{mg} / \mathrm{dL}$ (8.3-10.4 mg/dL), normal 25-hydroxyvitamin D $32 \mathrm{ng} / \mathrm{dL}$ (30-100 ng/dL), elevated 1,25-dihydroxyvitamin D $62 \mathrm{~g} /$ $\mathrm{mL}(20-45 \mathrm{pg} / \mathrm{mL})$, elevated intact PTH level $99.01 \mathrm{pg} / \mathrm{mL}$ (8-74 pg/mL), high normal $24 \mathrm{~h}$ urinary phosphate levels $1100 \mathrm{mg} / \mathrm{dL}$, and elevated FGF23 level $128 \mathrm{RU} / \mathrm{mL}(<108$ $\mathrm{RU} / \mathrm{mL}$ ). Complete blood count was within normal range. This is summarized in Table 1. Bone densitometry revealed a normal bone density and parathyroid scintigraphy was negative for adenoma. Considering clinical symptoms along with biochemical evidence of phosphate wasting as confirmed by low TRP and an unsuppressed FGF23 levels, a decision to consider oncogenic osteomalacia as an underlying cause for patients' symptoms was pursued. Whole-body bone scan demonstrated an increased radiotracer uptake in the elbows, spine, sacroiliac joints, knees, ankles and multiple ribs suggestive of an inflammatory process. MRI of paranasal sinuses revealed a large soft tissue mass completely occupying the right frontal, ethmoid, maxillary and sphenoid sinuses and expanding into the right nasal cavity suggestive of sinonasal polyposis (Fig. 1). ${ }^{99 m}$ Tc-Octreotide scan showed an abnormal area of increased uptake in the nasopharynx.

\section{Treatment}

The sinonasal mass was resected and immune histochemical studies showed positive S100 and negative CD34, CK, SMA, LCA, SAL4 and Caldesmin suggestive for glomus tumor. Ki67 index was 3-4\%.

\section{Outcome and follow-up}

Postoperatively, phosphate levels normalized to $3 \mathrm{mg} /$ dL on day 7. At 3 months follow-up visit, FGF23 was 10 $\mathrm{RU} / \mathrm{mL}$, PTH was $40 \mathrm{pg} / \mathrm{mL}$, total calcium was $8.9 \mathrm{mg} / \mathrm{dL}$, phosphate was $3.4 \mathrm{mg} / \mathrm{dL}$, and 25-hydroxyvitamin D 32 $\mathrm{ng} / \mathrm{mL}$, which were all within normal limits.

\section{Discussion}

Oncogenic osteomalacia, also known as 'tumor-induced osteomalacia (TIO)' is a paraneoplastic syndrome resulting in biochemical and pathological changes similar to hypophosphatemic rickets (1). Glomus tumor as a cause of tumor-induced osteomalacia is an extremely rare entity with only a limited number of published case reports.

Table 1 Laboratory results.

\begin{tabular}{l}
\hline Laboratory test \\
\hline Plasma glucose \\
Serum calcium, total \\
Serum phosphate \\
Serum albumin \\
Blood urea nitrogen \\
Serum creatinine \\
Serum aspartate transaminases \\
Serum alanine transaminases \\
Serum alkaline phosphatase \\
Intact parathyroid hormone \\
25-hydroxy vitamin D \\
1,25-dihydroxy vitamin D \\
Phosphate in $24 \mathrm{~h}$ urine (concentration $\mathrm{mg} / \mathrm{dL}$ or $\mathrm{mEq} / \mathrm{L}$ ) \\
Creatinine in $24 \mathrm{~h}$ urine (concentration $\mathrm{mg} / \mathrm{dL}$ ) \\
24 h urine calcium (concentration $\mathrm{mg} / \mathrm{dL}$ ) \\
Urine volume \\
Post-operative phosphate \\
FGF23
\end{tabular}

\begin{tabular}{l}
\hline \multicolumn{1}{c}{ Level } \\
\hline $104 \mathrm{mg} / \mathrm{dL}$ \\
$8.9 \mathrm{mg} / \mathrm{dL}$ \\
$1.5 \mathrm{mg} / \mathrm{dL}$ or $0.97 \mathrm{mEq} / \mathrm{L}$ \\
$4.2 \mathrm{mg} / \mathrm{dL}$ \\
$10 \mathrm{mg} / \mathrm{dL}$ \\
$0.9 \mathrm{mg} / \mathrm{dL}$ \\
$23 \mathrm{U} / \mathrm{L}$ \\
$27 \mathrm{U} / \mathrm{L}$ \\
$603 \mathrm{IU} / \mathrm{L}$ \\
$99.01 \mathrm{pg} / \mathrm{mL}$ \\
$32 \mathrm{ng} / \mathrm{mL}$ \\
$62 \mathrm{pg} / \mathrm{mL}$ \\
$1100 \mathrm{mg} / \mathrm{day}(88 \mathrm{mg} / \mathrm{dl}$ or $56.77 \mathrm{mEq} / \mathrm{L})$ \\
$614 \mathrm{mg} / \mathrm{day}(49.1 \mathrm{mg} / \mathrm{dL})$ \\
$165 \mathrm{mg} / \mathrm{day}(13.2 \mathrm{mg} / \mathrm{dL})$ \\
$1250 \mathrm{~mL}(12.5 \mathrm{dL})$ \\
$2.8 \mathrm{mg} / \mathrm{dL}$ \\
$128 \mathrm{RU} / \mathrm{mL}$
\end{tabular}

\begin{tabular}{c}
\hline Reference range \\
\hline $74-90 \mathrm{mg} / \mathrm{dL}$ \\
$8.3-10.4 \mathrm{mg} / \mathrm{dL}$ \\
$3.5-5.0 \mathrm{mg} / \mathrm{dL}$ \\
$3.4-5.4 \mathrm{mg} / \mathrm{dL}$ \\
$6-24 \mathrm{ng} / \mathrm{dL}$ \\
$0.60-1.10 \mathrm{mg} / \mathrm{dL}$ \\
$8-48 \mathrm{U} / \mathrm{L}$ \\
$7-45 \mathrm{U} / \mathrm{L}$ \\
$44-147 \mathrm{IU} / \mathrm{L}$ \\
$8.0-74.0 \mathrm{pg} / \mathrm{mL}$ \\
$20-80 \mathrm{ng} / \mathrm{mL}$ \\
$20-45 \mathrm{pg} / \mathrm{mL}$ \\
$360-1600 \mathrm{mg} / \mathrm{day}$ \\
$500-200 \mathrm{mg} / \mathrm{day}$ \\
$100-250 \mathrm{mg} / \mathrm{day}$ \\
\\
$3.5-5.0 \mathrm{mg} / \mathrm{dL}$ \\
$<$ or $=108 \mathrm{RU} / \mathrm{mL}$ \\
\hline
\end{tabular}




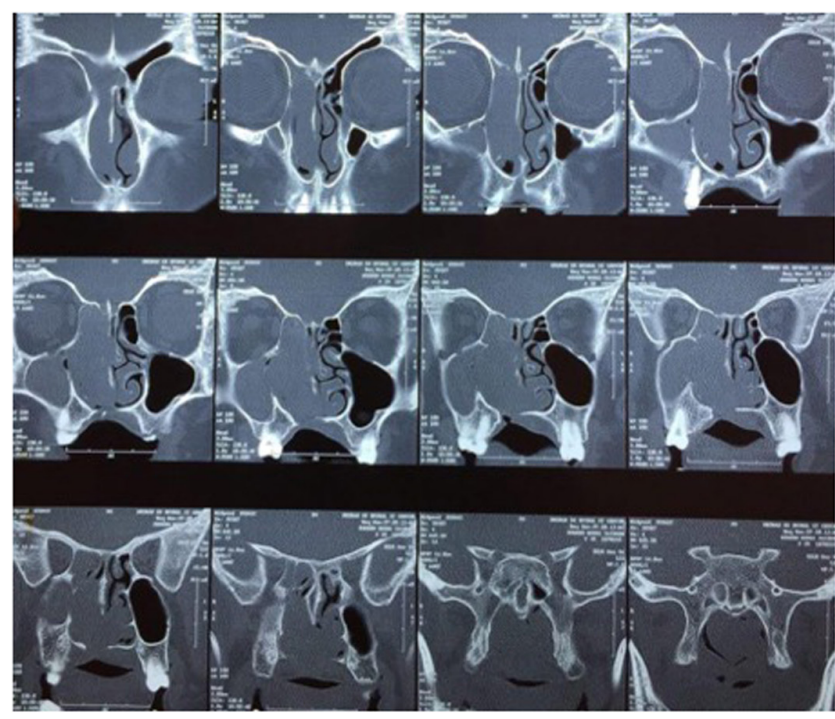

\section{Figure 1}

MRI of paranasal sinus revealed a large soft tissue mass completely occupying the right frontal, ethmoid, maxillary and sphenoid sinuses and expanding in to the right nasal cavity and deviating nasal septum towards the left side.

It is a mesenchymal tumor composed of modified smooth muscle cells arising from the glomus body, a specialized arteriovenous anastomosis that regulates heat in the skin. Glomus tumor is predominantly cutaneous, most commonly in the subungual region of the finger but can occur anywhere in the body, however, they are usually benign with very rare malignant variability (2).

The mesenchymal tumors secrete fibroblast growth factor 23 (FGF23). Excess FGF23 acts via FGF receptor 1 (FGFR1) on the kidneys and results in the decreased reabsorption of phosphate and decreased production of 1,25-dihydroxy vitamin D ultimately resulting in hypophosphatemia (3). This results in the biochemical finding of hypophosphatemia, low 1,25-dihydroxy vitamin $\mathrm{D}$ and increased urinary phosphate excretion along with the clinical symptoms of osteomalacia characterized by bone and muscle pain, muscle weakness, and fractures (4). In the majority of cases of oncogenic osteomalacia, FGF23 is high but it can also be inappropriate in the normal range (5). In our patient, FGF23 was inappropriately high, in the presence of concomitant hypophosphatemia and increased urinary phosphate excretion which led us to consider oncogenic osteomalacia as an underlying cause. As simultaneous plasma and urine values are more accurate when assessing fractional excretion of any molecule, particularly ones that can vary throughout the day, TmP/ GFR could not be successfully calculated in our case as we only had $24 \mathrm{~h}$ urine phosphate and creatinine values but not spot urine data. Nevertheless, a successful surgical outcome as suggested by rapid resolution of clinical symptoms, increase in phosphate level and drop in FGF23 levels after surgery retrospectively supports oncogenic osteomalacia as the underlying cause in our patient. Typically, these patients have normal PTH and calcium levels, however, with prolonged disease and treatment, they can develop secondary hyperparathyroidism resulting in elevated PTH levels (6).

Once the diagnosis is established, detection and localization of the causative tumor are the most important next step. As these mesenchymal tumors tend to be small in size, have an indolent course and are mysteriously hidden in unusual places, these are often difficult to localize on conventional imaging modalities (7). Imaging modalities involving whole-body MRI, ${ }^{18 F-F D G-P E T / C T, ~ o c t r e o t i d e ~}$ scan, and ${ }^{68} \mathrm{Ga}$-DOTATATE PET/CT have been successfully used to localize these tumors. One study compared ${ }^{18} \mathrm{~F}$ FDG PET/CT and ${ }^{68} \mathrm{Ga}$ DOTATATE PET/CT and suggested ${ }^{68} \mathrm{Ga}$ DOTATATE PET/CT be superior to ${ }^{18 \mathrm{~F}-F D G ~ P E T /}$ CT in diagnosing $\mathrm{TIO}$ and recommended to consider ${ }^{68} \mathrm{Ga}$ DOTATATE PET/CT as an initial diagnostic test for localization studies $(8,9)$. Despite these approaches, the success rates of tumor identification remain to be $65-80 \%$. Furthermore, due to this difficulty in tumor detection, there is often a significant delay between symptom onset and treatment of TIO (10).

Following localization of the tumor, the choice of treatment is the surgical resection of the tumor with a clear surgical margin to prevent tumor recurrence. FGF23 has a short half-life of approximately $45 \mathrm{~min}$ and hence surgical cure can be determined by a drop in FGF23 level postoperatively (11). Serum phosphate levels normalize between 5 and 10 post-operative days and the majority of patients feel better within days to weeks of tumor removal resulting in rapid and complete biochemical and clinical cures (7). Although the bone starts to heal immediately, it may vary depending on the severity of the disease process and may take years for significant recovery. Although late recurrence has been reported, it is extremely rare and can be seen with malignant mesenchymal tumors $(12,13)$.

When the tumor cannot be localized or is not surgically resectable, medical therapy is considered. Historically, phosphate and vitamin D supplementation used to be the main stay of treatment, however, recently Burosumab has become the preferred form of therapy and based on ongoing open-label Phase 2 study, it was FDA approved in June 2020 for use among patients with TIO. It has been shown to improve bone turnover markers and parameters of osteomalacia on bone biopsy. Furthermore, 
it also improves ambulation, reduces pain and results in sustained normalization of phosphate levels among treated patients (14). The goal of treatment among these patients with Burosumab or with phosphate and vitamin D supplementation is to achieve a serum phosphate in the lower end of the age-appropriate normal range.

\section{Declaration of interest}

The authors declare that there is no conflict of interest that could be perceived as prejudicing the impartiality of the research reported.

\section{Funding}

Funding for this case report was provided by the Education Department of Pikeville Medical Center, Pikeville, KY.

\section{Patient consent}

Written informed consent was obtained from the patient for the publication of submitted article.

\section{Author contribution statement}

$\mathrm{SH}, \mathrm{M} \mathrm{D}, \mathrm{M} \mathrm{K}, \mathrm{KV}, \mathrm{MH}$ D, I N, M N, M A, B H were directly involved in patient care and management. $\mathrm{M} \mathrm{K}$ and $\mathrm{R} \mathrm{R}$ were directly involved in writing the manuscript and literature reviews. $\mathrm{K} A$ helped with the diagnosis and treatment of the patient as well as edited the manuscript.

\section{References}

1 Minisola S, Peacock M, Fukumoto S, Cipriani C, Pepe J, Tella SH \& Collins MT. Tumour-induced osteomalacia. Nature Reviews: Disease Primers 20173 17044. (https://doi.org/10.1038/nrdp.2017.44)

2 Liapi-Avgeri G, Karabela-Bouropoulou V \& Agnanti N. Glomus tumor. A histological, histochemical and immunohistochemical study of the various types. Pathology, Research and Practice 1994190 2-10. (https:// doi.org/10.1016/S0344-0338(11)80490-5)

3 Martin A, David V \& Quarles LD. Regulation and function of the FGF23/klotho endocrine pathways. Physiological Reviews 201292 131-155. (https://doi.org/10.1152/physrev.00002.2011)
4 Jonsson KB, Zahradnik R, Larsson T, White KE, Sugimoto T, Imanishi Y, Yamamoto T, Hampson G, Koshiyama H, Ljunggren O, et al. Fibroblast growth factor 23 in oncogenic osteomalacia and X-linked hypophosphatemia. New England Journal of Medicine 2003348 1656-1663. (https://doi.org/10.1056/NEJMoa020881)

5 Florenzano P, Gafni RI \& Collins MT. Tumor-induced osteomalacia. Bone Reports 20177 90-97. (https://doi.org/10.1016/j.bonr.2017.09.002)

6 Farrow EG \& White KE. Tumor-induced osteomalacia. Expert Review of Endocrinology and Metabolism 20094 435-442. (https://doi. org/10.1586/eem.09.27)

7 Chong WH, Molinolo AA, Chen CC \& Collins MT. Tumor-induced osteomalacia. Endocrine-Related Cancer 201118 R53-R77. (https://doi. org/10.1530/ERC-11-0006)

8 Agrawal K, Bhadada S, Mittal BR, Shukla J, Sood A, Bhattacharya A \& Bhansali A. Comparison of 18F-FDG and 68Ga DOTATATE PET/ CT in localization of tumor causing oncogenic osteomalacia. Clinical Nuclear Medicine 201540 e6-e10. (https://doi.org/10.1097/ RLU.0000000000000460)

9 El-Maouche D, Sadowski SM, Papadakis GZ, Guthrie L, CottleDelisle C, Merkel R, Millo C, Chen CC, Kebebew E \& Collins MT. Ga-DOTATATE for tumor localization in tumor-induced osteomalacia. Journal of Clinical Endocrinology and Metabolism 2016101 3575-3581. (https://doi.org/10.1210/jc.2016-2052)

10 Hautmann AH, Hautmann MG, Kölbl O, Herr W \& Fleck M. Tumorinduced osteomalacia: an up-to-date review. Current Rheumatology Reports 201517 512. (https://doi.org/10.1007/s11926-015-0512-5)

11 Khosravi A, Cutler CM, Kelly MH, Chang R, Royal RE, Sherry RM, Wodajo FM, Fedarko NS \& Collins MT. Determination of the elimination half-life of fibroblast growth factor-23. Journal of Clinical Endocrinology and Metabolism 200792 2374-2377. (https://doi. org/10.1210/jc.2006-2865)

12 Ogose A, Hotta T, Emura I, Hatano H, Inoue Y, Umezu H \& Endo N. Recurrent malignant variant of phosphaturic mesenchymal tumor with oncogenic osteomalacia. Skeletal Radiology 200130 99-103. (https://doi.org/10.1007/s002560000306)

13 Folpe AL, Fanburg-Smith JC, Billings SD, Bisceglia M, Bertoni F, Cho JY, Econs MJ, Inwards CY, Jan de Beur SM, Mentzel T, et al. Most osteomalacia-associated mesenchymal tumors are a single histopathologic entity: an analysis of 32 cases and a comprehensive review of the literature. American Journal of Surgical Pathology 200428 1-30. (https://doi.org/10.1097/00000478-200401000-00001)

14 Imanishi Y, Ito N, Rhee Y, Takeuchi Y, Shin CS, Takahashi Y, Onuma H, Kojima M, Kanematsu M, Kanda H, et al. Interim analysis of a phase 2 open-label trial assessing Burosumab efficacy and safety in patients with tumor-induced osteomalacia. Journal of Bone and Mineral Research 202136 262-270. (https://doi.org/10.1002/ jbmr.4184)

Received in final form 10 February 2021

Accepted 25 May 2021 